\title{
The Exact Linearization and LQR Control of Semiactive Connected Hydropneumatic Suspension System
}

\author{
Xuyang Cao, Linlin Cao, and Dianlong Wang \\ Department of Mechanical Engineering, Dalian University of Technology, Liaoning, Dalian 116024, China \\ Correspondence should be addressed to Linlin Cao; caolinlin_yly@163.com
}

Received 2 February 2015; Revised 9 April 2015; Accepted 15 April 2015

Academic Editor: Zoltan Szabo

Copyright (C) 2015 Xuyang Cao et al. This is an open access article distributed under the Creative Commons Attribution License, which permits unrestricted use, distribution, and reproduction in any medium, provided the original work is properly cited.

\begin{abstract}
Based on differential geometry theory, the nonlinear system of connected hydropneumatic suspension was transformed to a linear one. What is more, it realized the decoupling and inverter between the control variables and system outputs. With LQR (Linear Quadratic Regulator) control theory, a semiactive system has been developed for connected hydropneumatic suspension in this paper. By AMESim/Simulink cosimulation, the results show that the semiactive connected hydropneumatic suspension decreases the vibration of upper vehicle quickly and reduces the impact acceleration strongly both in displacement and inroll angle. Moreover, the semiactive suspension could increase the suspension dynamic deflection, which would make the system reach balance quickly and keep small vibration amplitude under the effect of disturbance.
\end{abstract}

\section{Introduction}

Researches on intelligent suspension are popular in the past two decades. However, most of the researches are related to independent suspension and little research is involved in the connected suspension [1-6]. This paper considers the oil exchange among different hydrocylinders and accumulators of connected hydropneumatic suspension and proposes a solution to realize the semiactive control of connected hydropneumatic suspension, which needs to adjust two or more orifices at the same time. For the connected hydropneumatic suspension, the oil is exchanged among different hydrocylinders and accumulators through check valves and orifices, and their mathematic models have many nonlinear characteristics, as the analysis in [7]. Therefore, the semiactive connected hydropneumatic suspension system is a complicated multiple inputs and multiple outputs (MIMO) nonlinear system with time varying and strong coupling characteristics.

In order to solve the problems about how to transfer the nonlinear system to a linear system and how to realize the coordinated control of two or more orifices, the paper uses differential geometry theory and LQR control theory to build up the mathematic model, which is similar to $[4,5]$. With the differential geometry theory, the nonlinear mathematic model of connected hydropneumatic suspension system was transformed to a linear system. What is more, it realized the decoupling and inverter between the control variables and system outputs, which are important for the realization of feedback linearization and LQR control system for the semiactive connected hydropneumatic suspension. The cosimulation results of MATLAB/Simulink and AMESim show that the feedback linearization and LQR control system for the semiactive connected hydropneumatic suspension improve the properties of suspension compared to the passive connected hydro-pneumatic suspension.

\section{System Description}

In this study, a semiactive suspension was developed for connected hydropneumatic suspension. During the research, the passive dampers were replaced with hydroactive dampers to adapt to the suspension status in real time. Thus the semiactive suspension is called hydroactive suspension in the following.

Figure 1 displays the connected hydropneumatic suspension of $1 / 2$ vehicle model, which includes upper vehicle, hydraulic cylinders, accumulators, continuously variable damper throttle valves, and bottom vehicle. The tires are simplified as springs, as the models in $[3,4]$. Hydraulic 


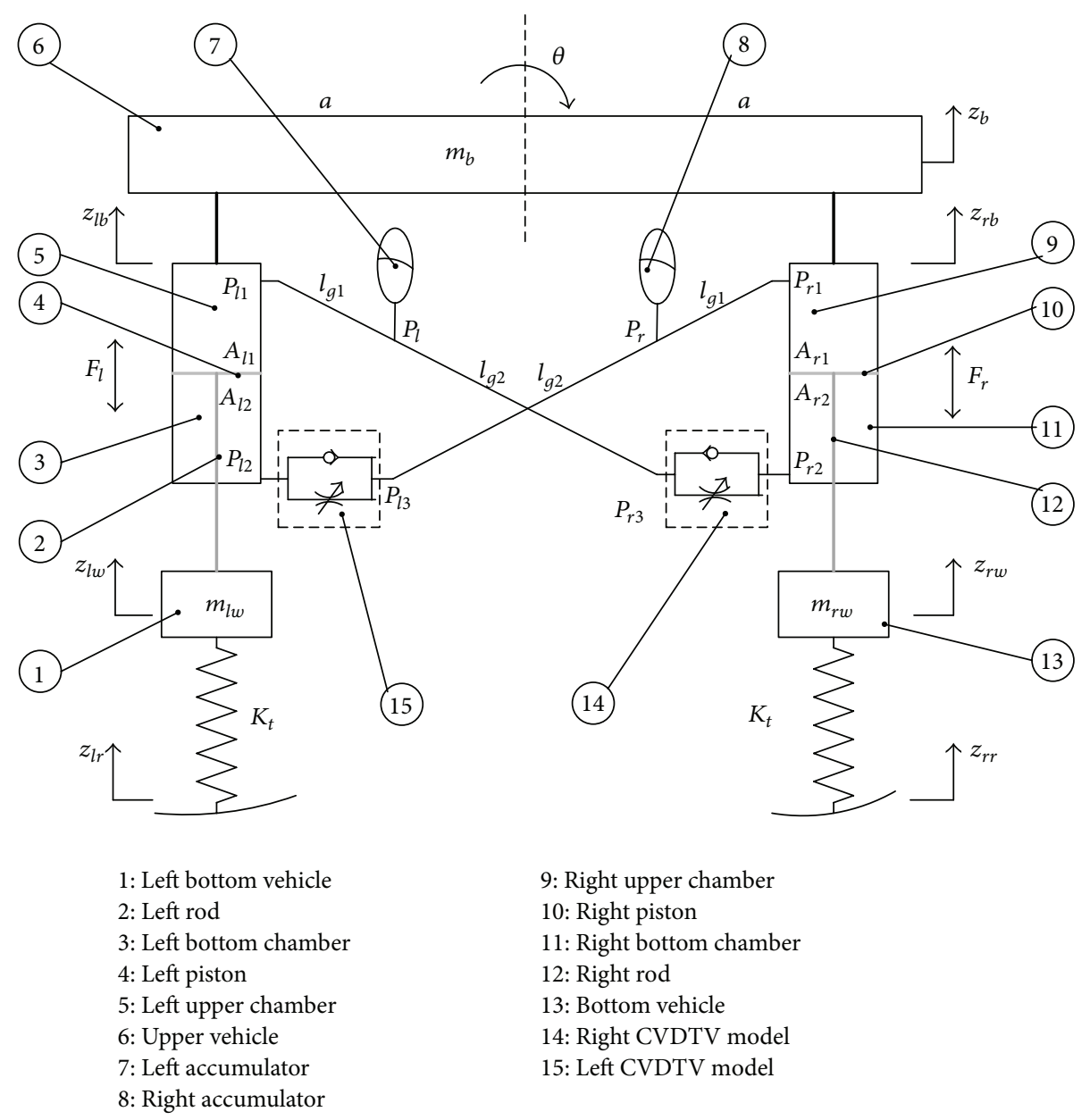

FIGURE 1: Semiactive connected hydropneumatic suspension.

cylinders are connected by hydraulic pipelines and continuously variable damper throttle valves, as shown in Figure 1. The upper chamber of left cylinder is connected with the bottom chamber of right cylinder, and the upper chamber of right cylinder is connected with the bottom chamber of left cylinder. The accumulators provide power for the suspension and act as springs that store and release energy. Additionally, the CVDTV model consists of check valve and damping valve, which could timely fill the oil of rod chamber through the check valve when the suspension is under the incentive effect and the damping valve is used to consume the vibration energy.

According to Figure 1, for the left cylinder, the rod moves outwards the cylinder during the rebound stroke when the check is closed and the amount of oil in left bottom chamber would flow to the right upper chamber and the right accumulator via the left orifice, which would compel the amount of oil in right bottom chamber flow to the left upper chamber and the left accumulator through the right orifice. In the bound stroke of left cylinder, the rod moves inwards the cylinder, which would increase the pressure of left upper chamber, and the oil will flow in the opposite direction when compared with the rebound stroke. Through the oil flow between two cylinders, the left and right suspension can keep pace with each other. In other words, when one side is lowered, the other also will be lowered, which could increase the stiffness of the lateral angle.

\section{Mathematic Model}

3.1. Nonlinear Mathematic Model of Connected Semiactive Suspension. The hydroactive suspension works under the adiabatic process. Therefore, the accumulator behaves under the ideal gas law [3]. Instantaneous pressure and volume of left accumulator $\left(P_{l}, V_{l}\right)$ and static pressure and volume $\left(P_{0}\right.$, $\left.V_{0}\right)$ satisfy the ideal gas equation:

$$
P_{l} V_{l}^{r}=P_{0} V_{0}^{r} .
$$

The oil volume of suspension cylinder and accumulator is constant. So the gas volume of left accumulator is $V_{l}=V_{0}$ $\left(z_{l w}-z_{l b}\right) A_{1}+\left(z_{r w}-z_{r b}\right) A_{2}$, and the instantaneous pressure of left accumulator is given by the following equation:

$$
P_{l}=\frac{P_{0} V_{0}^{r}}{\left[V_{0}-\left(z_{l w}-z_{l b}\right) A_{1}+\left(z_{r w}-z_{r b}\right) A_{2}\right]^{r}} .
$$


In the same way, the instantaneous pressure of right accumulator is given by

$$
P_{r}=\frac{P_{0} V_{0}^{r}}{\left[V_{0}-\left(z_{r w}-z_{r b}\right) A_{1}+\left(z_{l w}-z_{l b}\right) A_{2}\right]^{r}} .
$$

Damping hole and check valve of valve model can be simplified according to orifice throttling effect. Based on the theory of orifice throttling, the corresponding equations are given as

$$
\begin{aligned}
P_{l 2} & =P_{l 3}-\frac{\rho}{2}\left(\frac{A_{2} v_{1}}{\left(c_{z} A_{l z}+0.5 c_{d} A_{d}\left(1+\operatorname{sign}\left(v_{1}\right)\right)\right)}\right)^{2} \\
\cdot & \operatorname{sign}\left(v_{1}\right), \\
P_{r 2} & =P_{r 3}-\frac{\rho}{2}\left(\frac{A_{2} v_{2}}{\left(c_{z} A_{r z}+0.5 c_{d} A_{d}\left(1+\operatorname{sign}\left(v_{2}\right)\right)\right)}\right)^{2} \\
\cdot & \operatorname{sign}\left(v_{2}\right) .
\end{aligned}
$$

Considering the linear loss of pipeline, according to the hydromechanics theory, the following equations can be given:

$$
\begin{aligned}
& P_{l 1}=P_{l}+\lambda_{l 1 g} \frac{l_{g 1}}{d_{g}} \frac{\rho v_{l 1 g}^{2}}{2} \operatorname{sign}\left(v_{1}\right), \\
& P_{r 3}=P_{l}-\lambda_{g r 3} \frac{l_{g 2}}{d_{g}} \frac{\rho v_{g r 3}^{2}}{2} \operatorname{sign}\left(v_{2}\right), \\
& P_{r 1}=P_{r}+\lambda_{r 1 g} \frac{l_{g 1}}{d_{g}} \frac{\rho v_{r 1 g}^{2}}{2} \operatorname{sign}\left(v_{2}\right), \\
& P_{l 3}=P_{r}-\lambda_{g l 3} \frac{l_{g 2}}{d_{g}} \frac{\rho v_{g l 3}^{2}}{2} \operatorname{sign}\left(v_{1}\right) .
\end{aligned}
$$

Satisfying $c_{1}=D^{2} / d_{g 1}^{2}, c_{2}=\left(D^{2}-d^{2}\right) / d_{g 2}^{2}, v_{1}, v_{2}, v_{l 1 g}$, $v_{r 1 g}, v_{g r 3}$, and $v_{g l 3}$ are given by the following equations:

$$
\begin{aligned}
v_{1} & =\dot{z}_{l w}-\dot{z}_{l b}, \\
v_{2} & =\dot{z}_{r w}-\dot{z}_{r b}, \\
v_{l 1 g} & =v_{1} \frac{A_{l 1}^{2}}{A_{g 1}^{2}}=v_{1} \frac{D^{2}}{d_{g 1}^{2}}=v_{1} c_{1}, \\
v_{r 1 g} & =v_{2} \frac{A_{r 1}^{2}}{A_{g 1}^{2}}=v_{2} \frac{D^{2}}{d_{g 1}^{2}}=v_{2} c_{1}, \\
v_{g r 3} & =v_{2} \frac{A_{r 2}^{2}}{A_{g 2}^{2}}=v_{2} \frac{D^{2}-d^{2}}{d_{g 2}^{2}}=v_{2} c_{2}, \\
v_{g l 3} & =v_{1} \frac{A_{l 2}^{2}}{A_{g 2}^{2}}=v_{1} \frac{D^{2}-d^{2}}{d_{g 2}^{2}}=v_{1} c_{2},
\end{aligned}
$$

where $v_{1}$ and $v_{2}$ are the relative speeds between pistons and cylinders. $v_{l 1 g}, v_{r 1 g}, v_{g r 3}$, and $v_{g l 3}$ are the oil flow rates in the pipes.
According to (1) (5), satisfy

$$
\begin{aligned}
u_{1} & =\lambda_{l 1 g} \frac{l_{g 1}}{d_{g}} \frac{\rho c_{1}^{2}}{2} \operatorname{sign}\left(v_{1}\right) A_{1}+\lambda_{g l 3} \frac{l_{g 2}}{d_{g}} \frac{\rho c_{2}^{2}}{2} \\
& \cdot \operatorname{sign}\left(v_{1}\right) A_{2} \\
& +\frac{\rho}{2}\left(\frac{A_{2}}{c_{z} A_{l z}+0.5 c_{d} A_{d}\left(1+\operatorname{sign}\left(v_{1}\right)\right)}\right)^{2} \\
& \cdot \operatorname{sign}\left(v_{1}\right) A_{2}, \\
u_{2} & =\lambda_{r 1 g} \frac{l_{g 1}}{d_{g}} \frac{\rho c_{1}^{2}}{2} \operatorname{sign}\left(v_{2}\right) A_{1}+\lambda_{g r 3} \frac{l_{g 2}}{d_{g}} \frac{\rho c_{2}^{2}}{2} \\
& \cdot \operatorname{sign}\left(v_{2}\right) A_{2} \\
& +\frac{\rho}{2}\left(\frac{A_{2}}{c_{z} A_{r z}+0.5 c_{d} A_{d}\left(1+\operatorname{sign}\left(v_{2}\right)\right)}\right)^{2} \\
& \cdot \operatorname{sign}\left(v_{2}\right) A_{2}, \\
\psi_{1} & =P_{0} V_{0}^{r} A_{1}, \\
\psi_{2} & =P_{0} V_{0}^{r} A_{2} .
\end{aligned}
$$

The output forces of hydropneumatic suspension can be given by the following equations:

$$
\begin{aligned}
F_{l}= & \psi_{1}\left[V_{j}-\left(z_{l w}-z_{l b}\right) A_{1}+\left(z_{r w}-z_{r b}\right) A_{2}\right]^{-r} \\
& -\psi_{2}\left[V_{j}-\left(z_{r w}-z_{r b}\right) A_{1}+\left(z_{l w}-z_{l b}\right) A_{2}\right]^{-r} \\
& +\left(\dot{z}_{l w}-\dot{z}_{l b}\right)^{2} u_{1}, \\
F_{r}= & \psi_{1}\left[V_{j}-\left(z_{r w}-z_{r b}\right) A_{1}+\left(z_{l w}-z_{l b}\right) A_{2}\right]^{-r} \\
& -\psi_{2}\left[V_{j}-\left(z_{l w}-z_{l b}\right) A_{1}+\left(z_{r w}-z_{r b}\right) A_{2}\right]^{-r} \\
& +\left(\dot{z}_{r w}-\dot{z}_{r b}\right)^{2} u_{2} .
\end{aligned}
$$

Nonlinear equations of motion of the semiactive connected hydropneumatic are derived from Newton's second motion law. The corresponding equations are given as

$$
\begin{aligned}
m_{l w} \ddot{z}_{l w} & =K_{t}\left(z_{l r}-z_{l w}\right)-F_{l}-m_{l w} g, \\
m_{r w} \ddot{z}_{r w} & =K_{t}\left(z_{r r}-z_{r w}\right)-F_{r}-m_{r w} g, \\
m_{b} \ddot{z}_{b} & =F_{l}+F_{r}-m_{b} g, \\
J \ddot{\theta} & =F_{l}-F_{r} .
\end{aligned}
$$

\subsection{Process of Transforming the Nonlinear System into a Linear} One. In $[4,5]$, based on differential geometry theory, the nonlinear system was transformed into a linear one and realized active control of hydropneumatic suspension, but all of them were about independent suspension and the oil flow problems between suspension cylinders are not involved. In the following parts, the paper takes $u_{1}$ and $u_{2}$ as the control 
variables, based on differential geometry theory, transforms the nonlinear system into a linear one, and develops the LQR controller to realize the state feedback control system of semiactive connected hydropneumatic suspension. The state variables are introduced as follows:

$$
\begin{aligned}
& \left(x_{1}, x_{2}, x_{3}, x_{4}, x_{5}, x_{6}, x_{7}, x_{8}\right) \\
& \quad=\left(z_{l w}, \dot{z}_{l w}, z_{r w}, \dot{z}_{r w}, z_{b}, \dot{z}_{b}, \theta, \dot{\theta}\right) .
\end{aligned}
$$

When the suspension roll angle is very small, $\tan \theta \approx \theta$, thus the following equations can be given:

$$
\begin{aligned}
& z_{l b}=a \cdot \tan \theta+z_{b} \approx z_{b}+a \theta=x_{5}+a x_{7}, \\
& \dot{z}_{l b}=\dot{x}_{5}+a \dot{x}_{7}=x_{6}+a x_{8},
\end{aligned}
$$

$f(x)$

$$
=\left\{\begin{array}{l}
x_{2} \\
-\frac{K_{t}}{m_{l w}} x_{1}-\frac{\psi_{1}}{m_{l w}}\left[V_{j}-\left(x_{1}-x_{5}-a x_{7}\right) A_{1}+\left(x_{3}-x_{5}+a x_{7}\right) A_{2}\right]^{-r}+\frac{\psi_{2}}{m_{l w}}\left[V_{j}-\left(x_{3}-x_{5}+a x_{7}\right) A_{1}+\left(x_{1}-x_{5}-a x_{7}\right) A_{2}\right]^{-r} \\
x_{4} \\
-\frac{K_{t}}{m_{r w}} x_{3}-\frac{\psi_{1}}{m_{r w}}\left[V_{j}-\left(x_{3}-x_{5}+a x_{7}\right) A_{1}+\left(x_{1}-x_{5}-a x_{7}\right) A_{2}\right]^{-r}+\frac{\psi_{2}}{m_{r w}}\left[V_{j}-\left(x_{1}-x_{5}-a x_{7}\right) A_{1}+\left(x_{3}-x_{5}+a x_{7}\right) A_{2}\right]^{-r} \\
x_{6} \\
\frac{\psi_{1}-\psi_{2}}{m_{b}}\left[V_{j}-\left(x_{1}-x_{5}-a x_{7}\right) A_{1}+\left(x_{3}-x_{5}+a x_{7}\right) A_{2}\right]^{-r}+\frac{\psi_{1}-\psi_{2}}{m_{b}}\left[V_{j}-\left(x_{3}-x_{5}+a x_{7}\right) A_{1}+\left(x_{1}-x_{5}-a x_{7}\right) A_{2}\right]^{-r} \\
x_{8} \\
\frac{\psi_{1}+\psi_{2}}{J}\left[V_{j}-\left(x_{1}-x_{5}-a x_{7}\right) A_{1}+\left(x_{3}-x_{5}+a x_{7}\right) A_{2}\right]^{-r}+\frac{\psi_{1}+\psi_{2}}{J}\left[V_{j}-\left(x_{3}-x_{5}+a x_{7}\right) A_{1}+\left(x_{1}-x_{5}-a x_{7}\right) A_{2}\right]^{-r},
\end{array}\right.
$$$$
g(x)=\left\{\begin{array}{cc}
0 & 0 \\
-\frac{\left(x_{2}-x_{6}-a x_{8}\right)^{2}}{m_{l w}} & 0 \\
0 & 0 \\
0 & -\frac{\left(x_{4}-x_{6}+a x_{8}\right)^{2}}{m_{r w}} \\
0 & 0 \\
\frac{\left(x_{2}-x_{6}-a x_{8}\right)^{2}}{m_{l w}} & \frac{\left(x_{4}-x_{6}+a x_{8}\right)^{2}}{m_{r w}} \\
0 & 0 \\
\frac{\left(x_{2}-x_{6}-a x_{8}\right)^{2}}{J} & -\frac{\left(x_{4}-x_{6}+a x_{8}\right)^{2}}{J}
\end{array}\right\},
$$$$
p(x)=\left\{\begin{array}{ccc}
0 & 0 & 0 \\
\frac{K_{t}}{m_{l w}} & 0 & -1 \\
0 & 0 & 0 \\
0 & \frac{K_{t}}{m_{r w}} & -1 \\
0 & 0 & 0 \\
0 & 0 & -1 \\
0 & 0 & 0 \\
0 & 0 & 0
\end{array}\right\},
$$

$y=\left\{\begin{array}{l}x_{5} \\ x_{7} .\end{array}\right.$
Thus, the nonlinear semiactive connected hydropneumatic suspension model can be transformed to an affine nonlinear model as

$$
\begin{aligned}
& \dot{x}=f(x)+g(x) u+p(x) z \\
& y=h(x)
\end{aligned}
$$

where 
Based on the decoupling condition of the nonlinear system, the state feedbacks can be selected as in the following equations $[8,9]$ :

$$
\begin{aligned}
u & =\alpha(x)+\beta(x) v, \\
\alpha(x) & =-A^{-1}(x) b(x), \\
\beta(x) & =A^{-1}(x), \\
b(x) & =\left[L_{f}^{r 1} h_{1}(x), L_{f}^{r 2} h_{2}(x)\right]^{T}, \\
\dot{x} & =f(x)+g(x) \alpha(x)+g(x) \beta(x) v, \\
y_{1} & =h_{1}(x), \\
y_{2} & =h_{2}(x),
\end{aligned}
$$

where

$$
A(x)=\left[\begin{array}{ll}
L_{g 1} L_{f}^{r_{1}-1} h_{1}(x) & L_{g 2} L_{f}^{r_{1}-1} h_{1}(x) \\
L_{g 1} L_{f}^{r_{2}-1} h_{2}(x) & L_{g 2} L_{f}^{r_{2}-1} h_{2}(x)
\end{array}\right] .
$$

Thus, the nonlinear system model can be transformed into a linear system as in following state space equations:

$$
\begin{aligned}
& \dot{x}=A x+B v+G z, \\
& y=C x+D v,
\end{aligned}
$$

where

$$
\left.\begin{array}{rl}
A & =\left[\begin{array}{cccccccc}
0 & 1 & 0 & 0 & 0 & 0 & 0 & 0 \\
-\frac{K_{t}}{m_{l w}} & 0 & 0 & 0 & 0 & 0 & 0 & 0 \\
0 & 0 & 0 & 1 & 0 & 0 & 0 & 0 \\
0 & 0 & -\frac{K_{t}}{m_{r w}} & 0 & 0 & 0 & 0 & 0 \\
0 & 0 & 0 & 0 & 0 & 1 & 0 & 0 \\
0 & 0 & 0 & 0 & 0 & 0 & 0 & 0 \\
0 & 0 & 0 & 0 & 0 & 0 & 0 & 1 \\
0 & 0 & 0 & 0 & 0 & 0 & 0 & 0
\end{array}\right], \\
B & =\left[\begin{array}{cc}
0 & 0 \\
-\frac{m_{b}}{2 m_{l w}} & -\frac{J}{2 m_{l w}} \\
0 & 0 \\
-\frac{m_{b}}{2 m_{r w}} & \frac{J}{2 m_{r w}} \\
0 & 0 \\
1 & 0 \\
0 & 0 \\
0 & 1
\end{array}\right], \\
0
\end{array}\right]
$$

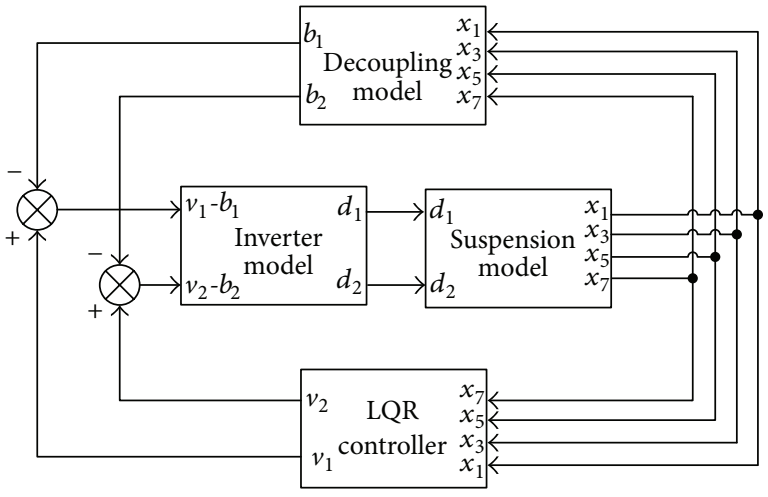

FIGURE 2: Control model of semiactive connected hydropneumatic suspension.

$$
G=\left[\begin{array}{ccc}
0 & 0 & 0 \\
\frac{K_{t}}{m_{l w}} & 0 & -1 \\
0 & \frac{K_{t}}{m_{r w}} & -1 \\
0 & 0 & 0 \\
0 & 0 & -1 \\
0 & 0 & 0 \\
0 & 0 & 0 \\
0 & 0 & 0
\end{array}\right] .
$$

\section{Control Model of Semiactive Connected Hydropneumatic Suspension}

4.1. Control Model. Figure 2 is the control model of semiactive connected hydropneumatic suspension. There are 4 parts in the semiactive connected hydropneumatic suspension, decoupling model, inverter model, suspension model, and LQR controller. With (15), the decoupling model and inverter model can be completed easily. Suspension model can be built up with the AMESim software, and the controller will be designed with the MATLAB/Simulink.

4.2. Optimal Controller Design. In [6], the gain matrix can be derived from dynamic programming by calculating the equation of Hamilton-Jacobi-Bellman (HJB). With the observer design, the fully active suspension control is possible, based on optimal control theories [10]. Reference [11] presents the method of how to select input/output variables. The control structure selections are studied from economics and process in $[12,13]$. Reference [14] conducts a comprehensive research about control structure selection. Reference [15] assumes that all the states are available and can be measured accurately; thus the regulatory feedback can be considered like $v=-K \cdot x$ and $K$ is the feedback gain matrix.

Just considering that the displacement and the roll angle of upper vehicle are not enough, the suspension deflection 
and the performance of bottom vehicle also should be considered. Therefore, it needs to add output variables during design process of the LQR controllers. Thereby, the equation $y=h(x)$ in formula (13) can be substituted with the following formula:

$$
\begin{aligned}
& y \\
& =\left\{\begin{array}{l}
x_{5} \\
x_{7} \\
0.5 x_{1}+0.5 x_{3}-x_{5} \\
-\frac{k_{t}}{m_{l w}} x_{1}-\frac{m_{b}}{2 m_{l w}} v_{1}-\frac{J}{2 m_{l w}} v_{2}+\frac{k_{t}}{m_{l w}} z_{l r}-g \\
-\frac{k_{t}}{m_{r w}} x_{3}-\frac{m_{b}}{2 m_{r w}} v_{1}+\frac{J}{2 m_{r w}} v_{2}+\frac{k_{t}}{m_{r w}} z_{r r}-g .
\end{array}\right.
\end{aligned}
$$

Formula (19) also can be written as matrix formula

$$
Y=C X+D v+P z
$$

where

$$
\begin{aligned}
C & =\left[\begin{array}{cccccccc}
0 & 0 & 0 & 0 & 1 & 0 & 0 & 0 \\
0 & 0 & 0 & 0 & 0 & 0 & 1 & 0 \\
0.5 & 0 & 0.5 & 0 & -1 & 0 & 0 & 0 \\
-\frac{k_{t}}{m_{l w}} & 0 & 0 & 0 & 0 & 0 & 0 & 0 \\
0 & 0 & -\frac{k_{t}}{m_{r w}} & 0 & 0 & 0 & 0 & 0
\end{array}\right], \\
D & =\left[\begin{array}{ccc}
0 & 0 \\
0 & 0 \\
0 & 0 \\
-\frac{m_{b}}{2 m_{l w}} & -\frac{J}{2 m_{l w}} \\
-\frac{m_{b}}{2 m_{r w}} & \frac{J}{2 m_{r w}}
\end{array}\right], \\
P & =\left[\begin{array}{ccc}
0 & 0 & 0 \\
0 & 0 & 0 \\
0 & 0 & 0 \\
\frac{k_{t}}{m_{l w}} & 0 & -1 \\
0 & \frac{k_{t}}{m_{l w}} & -1
\end{array}\right] .
\end{aligned}
$$

The cost function, shown in (22), represents the characteristics of output variables or input variables required. It designs the control signal $v$ by making the output variables and input variables' performance indexes minimized:

$$
J=\int_{0}^{\infty}\left(Y^{T} q Y+v^{T} r v\right) d t
$$

TABLE 1: Parameters of simulation model.

\begin{tabular}{lc}
\hline Parameter & Value \\
\hline Cylinder installation distance $(a)$ & $1.0 \mathrm{~m}$ \\
Upper vehicle quality $\left(m_{b}\right)$ & $12000 \mathrm{Kg}$ \\
The moment of inertia of upper vehicle $(J)$ & $4000 \mathrm{Nm}^{2}$ \\
Bottom vehicle quality $\left(m_{w}\right)$ & $500 \mathrm{Kg}$ \\
Tire stiffness $\left(K_{t}\right)$ & $3000000 \mathrm{~N} / \mathrm{m}$ \\
Cylinder bore $(D)$ & $0.11 \mathrm{~m}$ \\
The piston rod diameter $(d)$ & $0.09 \mathrm{~m}$ \\
Balance pressure of accumulator $\left(P_{j}\right)$ & $9.25 \times 10^{6} \mathrm{~Pa}$ \\
Accumulator volume $\left(V_{j}\right)$ & $1.3 \mathrm{~L}$ \\
\hline
\end{tabular}

Ignoring the disturbance and combining matrix formula (20), (22) can be written as

$$
\begin{aligned}
J= & \lim _{T \rightarrow \infty} \frac{1}{T} \int_{0}^{T}\left[X^{T}\left(C^{T} q C\right) X+v^{T}\left(r+D^{T} q D\right) v\right. \\
& \left.+2 X^{T}\left(C^{T} q D\right) v\right] d t .
\end{aligned}
$$

Satisfy

$$
\begin{aligned}
& Q=C^{T} q C, \\
& R=r+D^{T} q D, \\
& N=C^{T} q D .
\end{aligned}
$$

$q$ and $r$ are weight matrixes, which could be got with trial and error method. From the state space system, the controlled variables $v_{1}$ and $v_{2}$ represent the roll angle acceleration and vibration acceleration of the upper vehicle, respectively. The gain $K$ can be obtained through MATLAB command $\operatorname{lqr}(A, B, Q, R, N)$.

\section{Simulation and Results}

The parameters of simulation model are based on the LTM1500 all-terrain crane, as is shown in Table 1. And the MTALAB/Simulink simulation model is shown in Figure 3.

In order to demonstrate the quality of system, the vehicle is assumed to travel over a single sin bump, which is similar to that in [16-18]. In this paper, the model considered the two situations. Firstly, two disturbances are applied to the two-side wheels at the same time. Secondly, disturbances are applied to the two-side wheels at different time. Figure 4 is the sin bump disturbance with $40 \mathrm{~mm}$ in height and $400 \mathrm{~mm}$ in length.

Figure 5 shows the performance of suspension system to the first situation, in which disturbances are applied to the two-side wheels at the same time. Therefore, it would not cause suspension body sway. At the start, because of the gravity, the suspension body will descend about 20 millimeters, which fits Figures 5(a) and 6(a). The simulation results of the first situation show that the semiactive system decreases suspension body vibration and suspension deflection compared to the passive one. The improvement is clear 


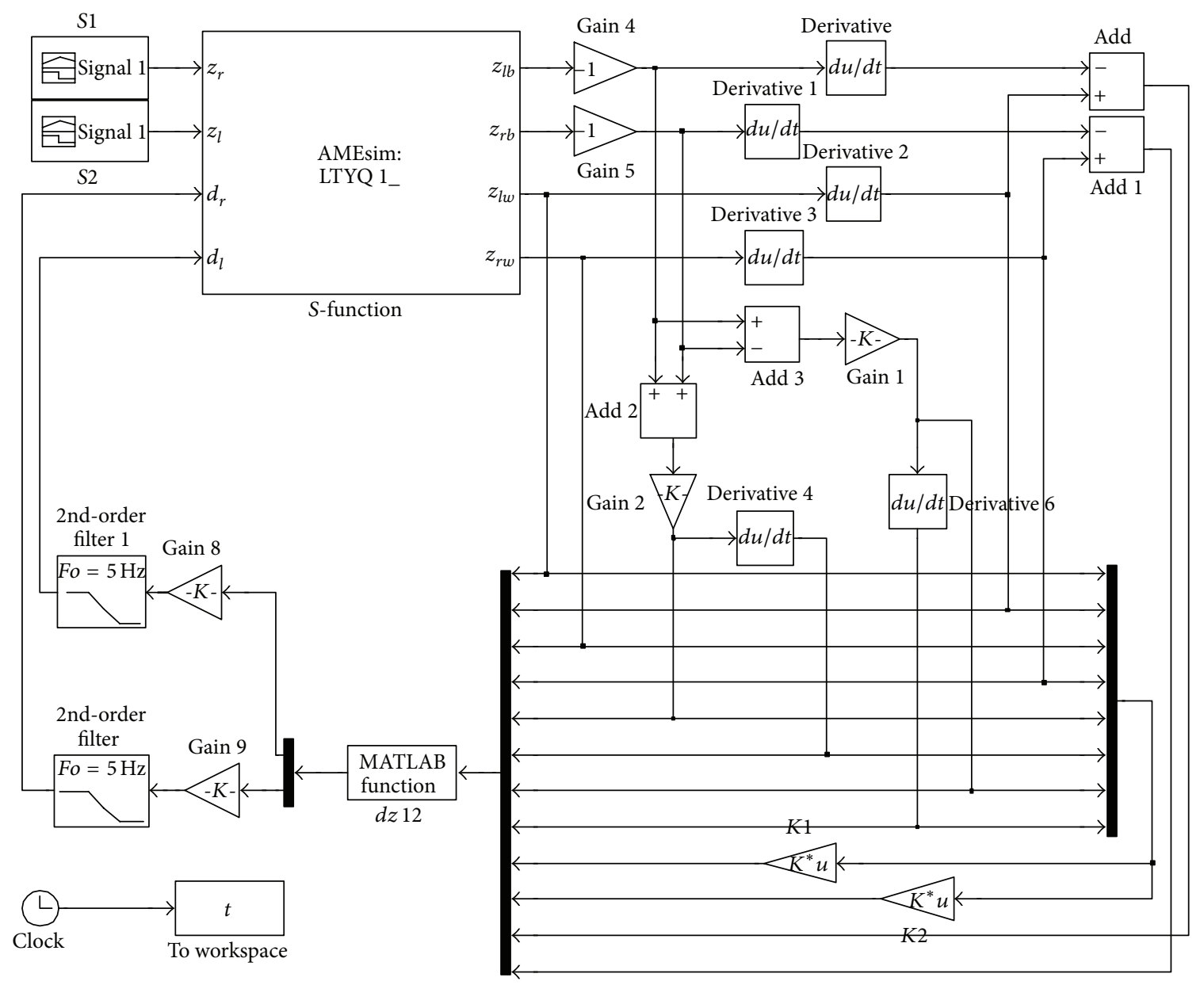

FIGURE 3: MTLAB/Simulink simulation model.

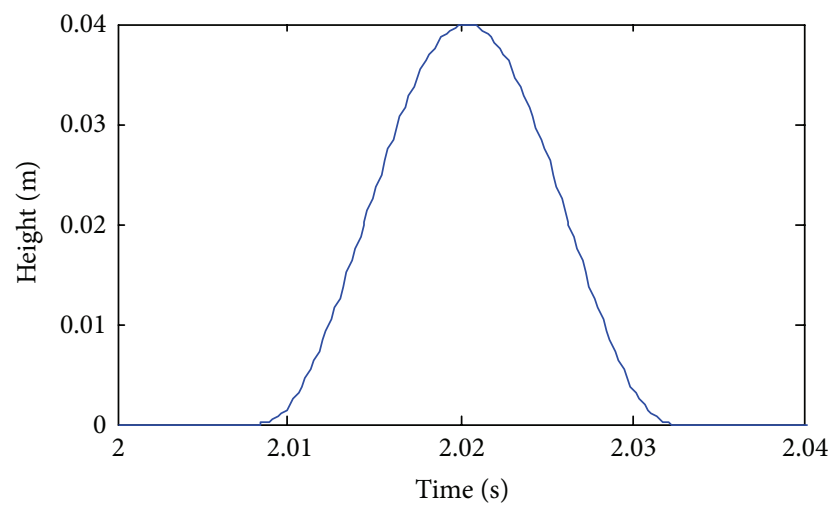

FIgURE 4: Sin bump disturbance.

in the RMS values relative to the balance position of body displacement and suspension deflection, which decrease by $8.3 \%$ and $11.5 \%$ reduction, respectively. Moreover, the result of body acceleration shows that the maximum value has a 7.7\% reduction, which indicates that the semiactive system weakens the peak impact. These RMS values and maximum values of both semiactive suspension and passive suspension for the first situation are listed in Table 2.
The first situation cannot assess the body roll angle performance, which is an important characteristic for resisting overturn. However, in the second situation, the disturbances are applied to the two-side wheels at different time, so it will cause for the suspension roll an angle. Figure 6 is the simulation results of the second situation. Compared with the passive suspension, the semiactive suspension improves the suspension vibration performance, too. It makes 6.7\%, 


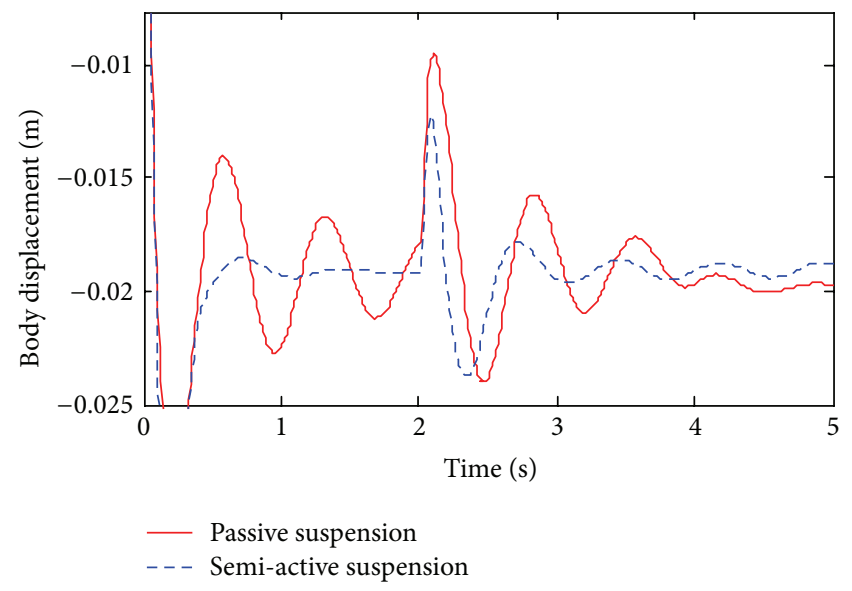

(a) Body displacement

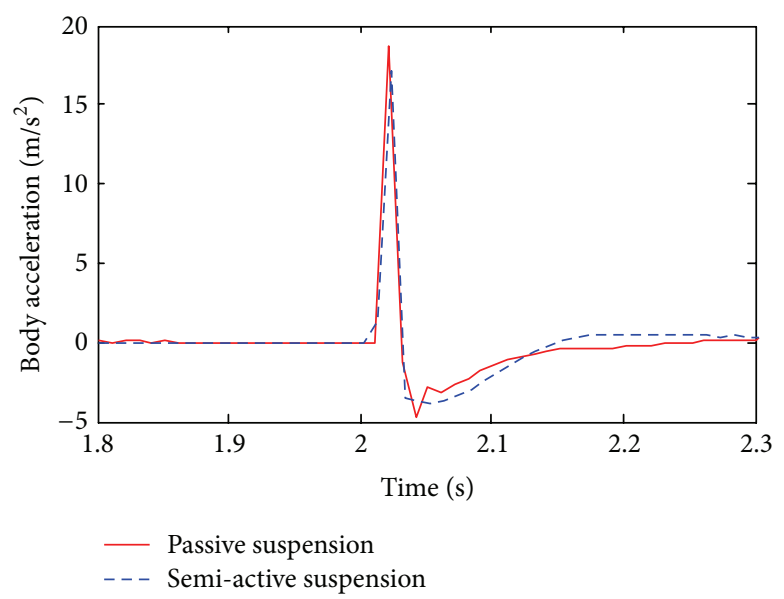

(b) Body acceleration

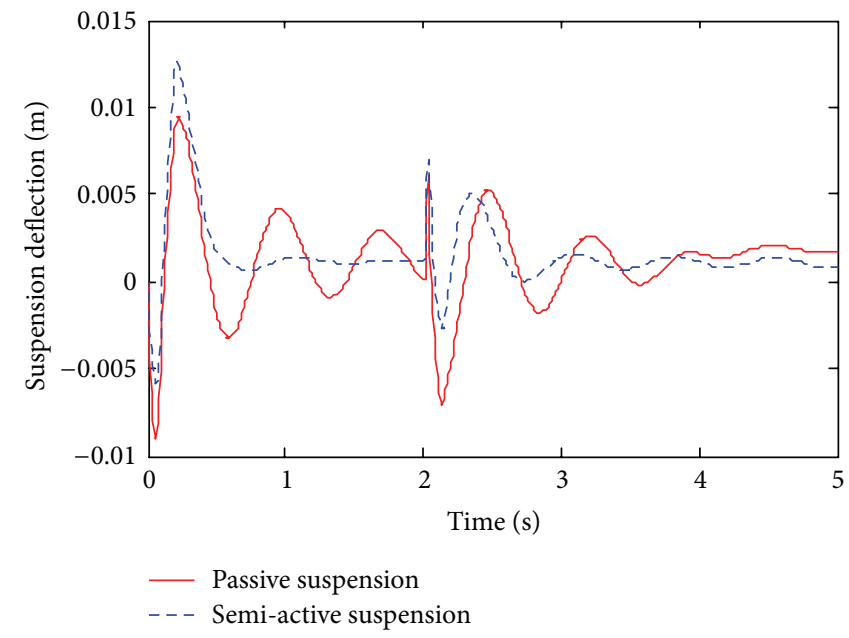

(c) Suspension deflection

FIGURE 5: Suspension system to the first situation.

TABLE 2: Comparison of the performance of semiactive system and passive system for the first situation.

\begin{tabular}{lcccc}
\hline \multirow{2}{*}{ Variables } & \multicolumn{2}{c}{ Semiactive } & \multicolumn{2}{c}{ Passive } \\
& RMS & Maximum & RMS & Maximum \\
\hline $\begin{array}{l}\text { Body } \\
\text { displacement } \\
\begin{array}{l}\mathrm{m}) \\
\text { Body }\end{array}\end{array}$ & 0.0033 & 0.007 & 0.0036 & 0.010 \\
$\begin{array}{l}\text { acceleration } \\
\left(\mathrm{m} / \mathrm{s}^{2}\right)\end{array}$ & 1.2201 & 17.206 & 1.1713 & 18.649 \\
$\begin{array}{l}\text { Suspension } \\
\text { deflection }(\mathrm{m})\end{array}$ & 0.0023 & 0.0057 & 0.0026 & 0.0087 \\
\hline
\end{tabular}

9.1\% reductions, respectively, for the RMS values relative to the balance position of body displacement and suspension deflection, compared with the passive one. Moreover, the maximum values of body acceleration and body roll acceleration, which have $15.6 \%, 26.3 \%$ reductions compared with passive suspension, also show that the semiactive suspension weakens the peak impact. These RMS values and maximum values of both semiactive suspension and passive suspension for the second situation are listed in Table 3. For the second situation, the suspension has two impacts, so the maximum values listed in Table 3 are the mean values of the twice impact maximum values.

\section{Conclusions}

In this paper, a semiactive system has been developed to connect hydropneumatic suspension with feedback linearization and LQR control theory. To demonstrate the quality of semiactive system, it uses the sin bump as the disturbance and considers two situations, in which the disturbances are applied to two wheels at same time and at different time, respectively. From the results of AMESim/Simulink cosimulation and the analysis of the data, it is proved that the semiactive system could improve the performances of suspension vibration obviously. For the first situation and the second situation, under the semiactive control, the RMS values of body displacement and suspension deflection 


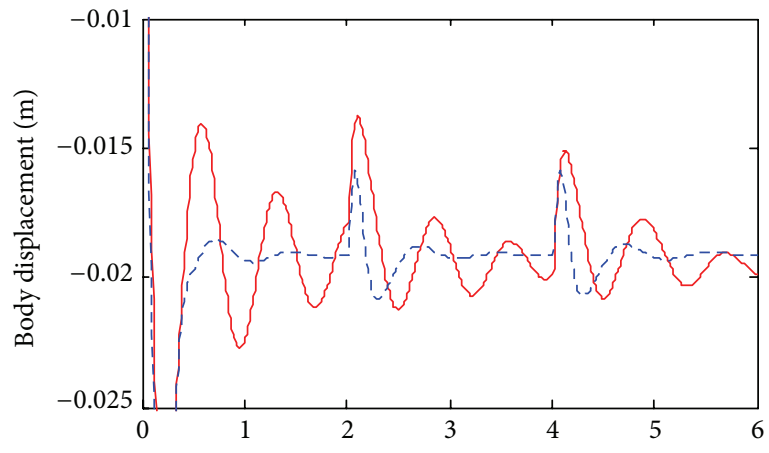

(a) Body displacement

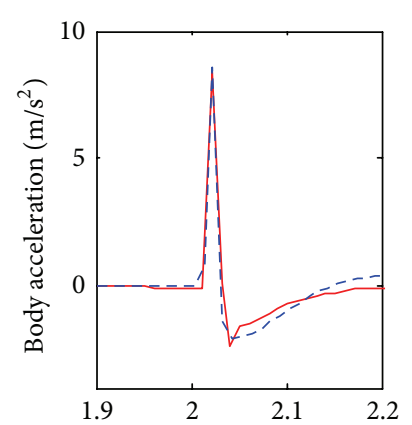

(c) Partial enlarged details of body acceleration

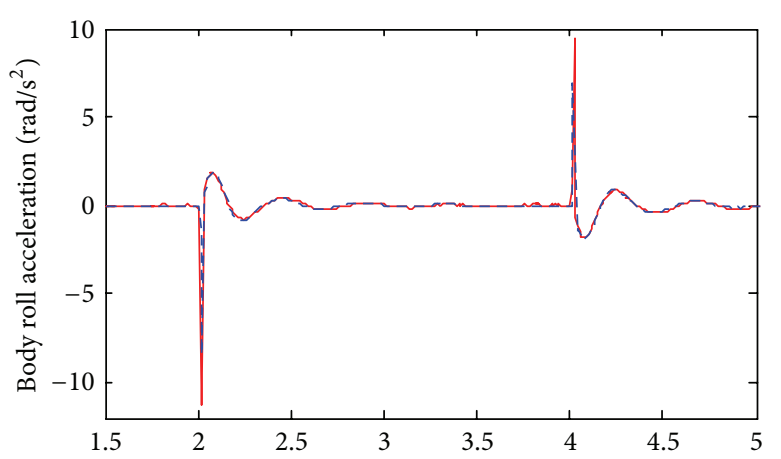

(e) Body roll angle acceleration

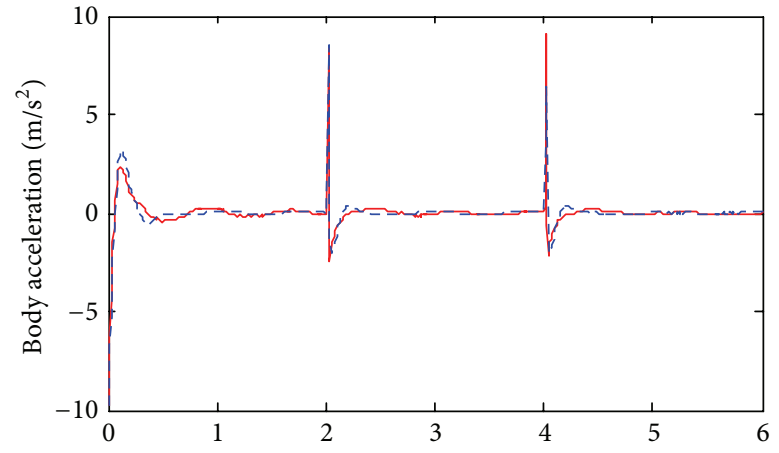

(b) Body acceleration

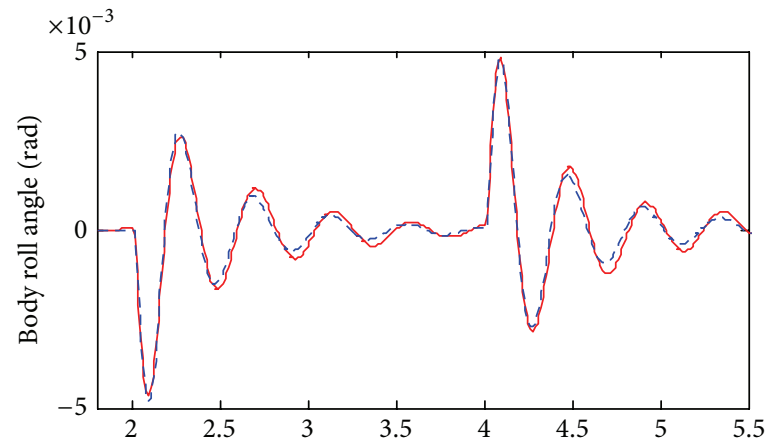

(d) Body roll angle
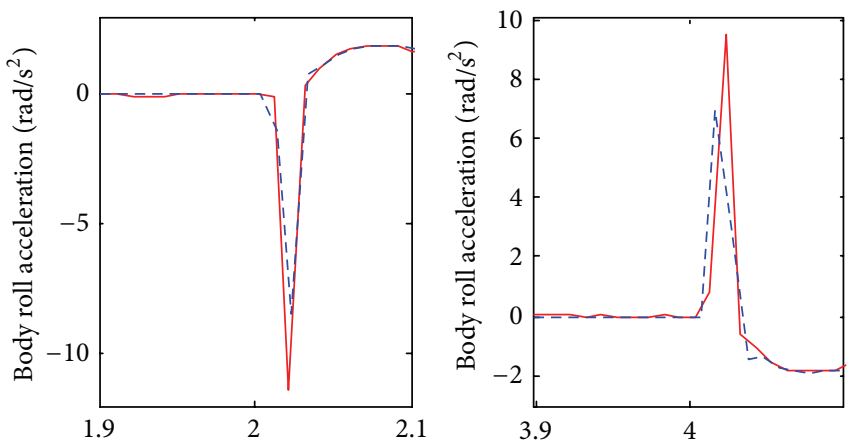

(f) Partial enlarged details of body roll angle acceleration

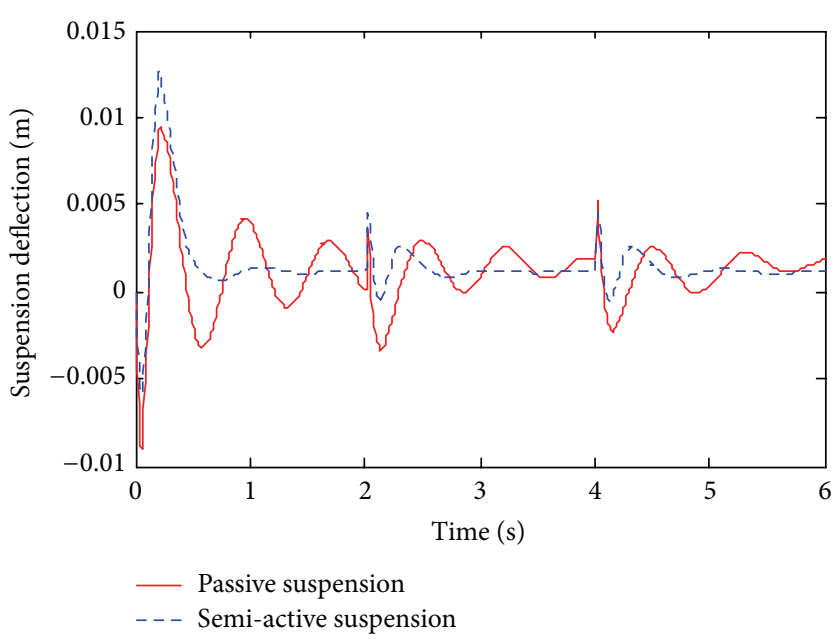

(g) Suspension deflection

FIgURE 6: Suspension system to the second situation. 
TABLE 3: Comparison of the performance of semiactive system and passive system for the second situation.

\begin{tabular}{lcccc}
\hline \multirow{2}{*}{ Variables } & \multicolumn{2}{c}{ Semiactive } & \multicolumn{2}{c}{ Passive } \\
& RMS & Maximum & RMS & Maximum \\
\hline $\begin{array}{l}\text { Body } \\
\text { displacement } \\
(\mathrm{m})\end{array}$ & 0.0028 & 0.0033 & 0.0030 & 0.0048 \\
$\begin{array}{l}\text { Body } \\
\text { acceleration } \\
\left(\mathrm{m} / \mathrm{s}^{2}\right)\end{array}$ & 0.9382 & 7.442 & 0.8709 & 8.718 \\
$\begin{array}{l}\text { Roll angle (rad) } \\
\text { Roll angle }\end{array}$ & 0.001 & 0.0048 & 0.001 & 0.0047 \\
$\begin{array}{l}\text { acceleration } \\
\left.\text { (rad } / \mathrm{s}^{2}\right)\end{array}$ & 0.5790 & 7.69 & 0.6910 & 10.44 \\
$\begin{array}{l}\text { Suspension } \\
\text { deflection }(\mathrm{m})\end{array}$ & 0.0020 & 0.0037 & 0.0022 & 0.0042 \\
\hline
\end{tabular}

have $8.3 \%, 11.5 \%$ and $6.7 \%, 9.1 \%$ reductions, respectively. Otherwise, the semiactive suspension also weakens the peak impact. The maximum values of body acceleration and body roll acceleration show that semiactive suspension has the reduction of $7.7 \%$, - and $15.6 \%, 26.3 \%$ to the two situations.

\section{Conflict of Interests}

The authors declare that there is no conflict of interests regarding the publication of this paper.

\section{References}

[1] E. Sarshari and A. K. Sedigh, "Selection of sensors for hydroactive suspension system of passenger car with input-output pairing considerations," Journal of Dynamic Systems, Measurement and Control, vol. 135, no. 1, Article ID 011004, 2013.

[2] E. Sarshari, N. Asadi, and R. Yousefi, "Design of hydractive optimal suspension for a passenger vehicle," in Proceedings of the ASME International Mechanical Engineering Congress \& Exposition (IMECE '10), pp. 351-359, Vancouver, Canada, November 2010.

[3] S. M. El-Demerdash and D. A. Crolla, "Effect of non-linear components on the performance of a hydro-pneumatic slow-active suspension system," Proceedings of the Institution of Mechanical Engineers, Part D: Journal of Automobile Engineering, vol. 210, no. 1, pp. 23-33, 1996.

[4] J.-W. Shi, X.-W. Li, and J.-W. Zhang, "Feedback linearization control for missile launch vehicle active hydropneumatic suspension," Journal of System Simulation, vol. 21, no. 23, pp. 76177639, 2009.

[5] M.-T. Yao, Z. Li, and L. Gu, "LQR control for vehicle semi-active hydro-pneumatic suspension based on differential geometry theory," Transaction of Beijing Institute of Technology, vol. 31, no. 5, pp. 519-523, 2011.

[6] K. Okano, K. Hagino, and H. Oya, "Decreasing the value of specified cost function by adaptive controller based on modified ACLF for a class of nonlinear systems," Journal of Control Science and Engineering, vol. 2014, Article ID 280951, 9 pages, 2014.
[7] X. Fang, Research on Connected Hydro-Pneumatic Suspension System, Dalian University of Technology, Dalian, China, 2011.

[8] P. Y. Cui, X. P. Xue, and C. Chen, "Differential geometric approach for exact linearization of nonlinear system," Flight Dynamics, vol. 11, pp. 1-9, 1993.

[9] P. Y. Cui and X. P. Xue, "Linearization with state feedback for multi-input nonlinear systems," Journal of Harbin Institute of Technology, vol. 25, no. 3, pp. 84-89, 1993.

[10] H. Taghirad and E. Esmailzadeh, "Automobile passenger comfort assured through LQG/LQR active suspension," Journal of Vibration and Control, vol. 4, no. 5, pp. 603-618, 1998.

[11] M. van de Wal and B. de Jager, "A review of methods for input/output selection," Automatica, vol. 37, no. 4, pp. 487-510, 2001.

[12] L. Narraway and J. Perkins, "Selection of process control structure based on economics," Computers \& Chemical Engineering, vol. 18, supplement 1, pp. S511-S515, 1994.

[13] E. A. Wolff and S. Skogestad, "Operability of integrated plants," in Proceedings of the Symposium on Process System Engineering (PSE '94), pp. 63-70, Kyongju, Republic of Korea, June 1994.

[14] A. Khaki-Sedigh and B. Moaveni, Control Configuration Selection for Multivariable Plants, Springer, New York, NY, USA, 2009.

[15] E. Sarshari and A. K. Sedigh, "Optimal control of ride comfort of a passenger car: comparison between the hydro active and the fully active suspension systems," SAE Technical Paper No. 2010-01-1913, 2010.

[16] S. de Bruyne, J. Anthonis, M. Gubitosa, H. van der Auweraer, W. Desmet, and J. Swevers, "Model based actuator management for a hydraulic active suspension system: improving comfort performance by advanced control," in Proceedings of the ASME International Mechanical Engineering Congress \& Exposition, IMECE 2011-63962, pp. 263-271, ASME, Denver, Colo, USA, November 2011.

[17] M. Taghipour, D. Shahriari, and A. Shahsavari, "Active suspension systems with optimal jerk control," in Proceedings of the 8th Biennial ASME Conference on Engineering Systems Design and Analysis (ESDA '06), July 2006.

[18] A. A. Fayed, M. B. Trabia, and M. M. ElMadany, "Optimization of weighting paprameters for an active suspension system of a vehicle," in Proceedings of the ASME International Mechanical Engineering Congress \& Exposition (IMECE '08), IMECE 200866521, pp. 893-901, Boston, Mass, USA, November 2008. 

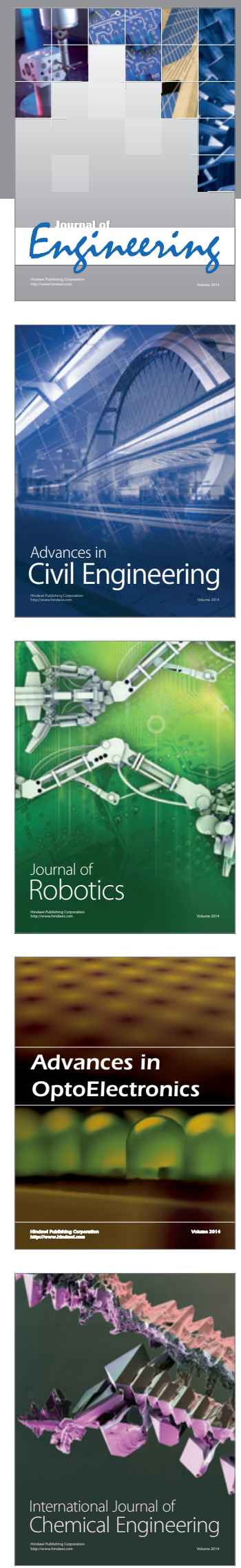

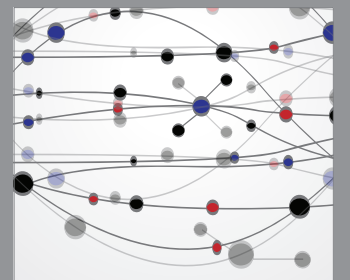

The Scientific World Journal
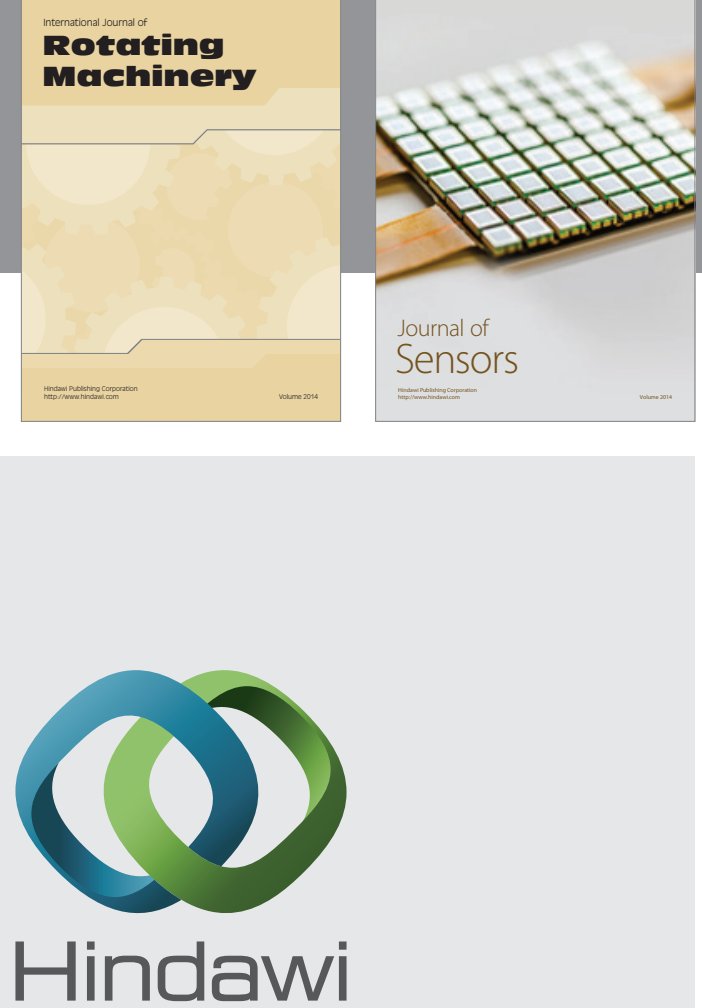

Submit your manuscripts at http://www.hindawi.com
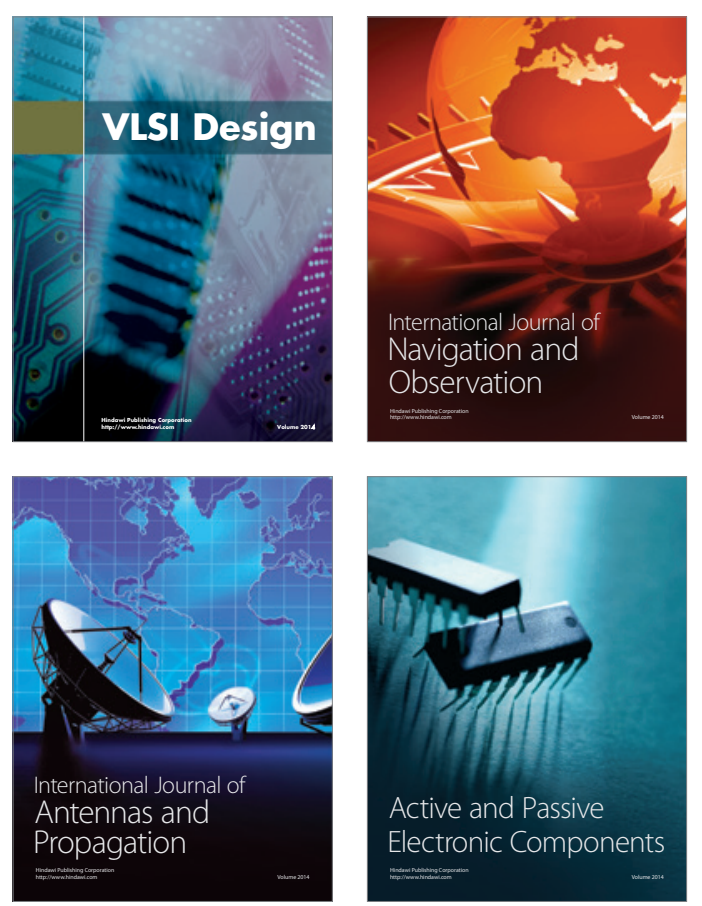
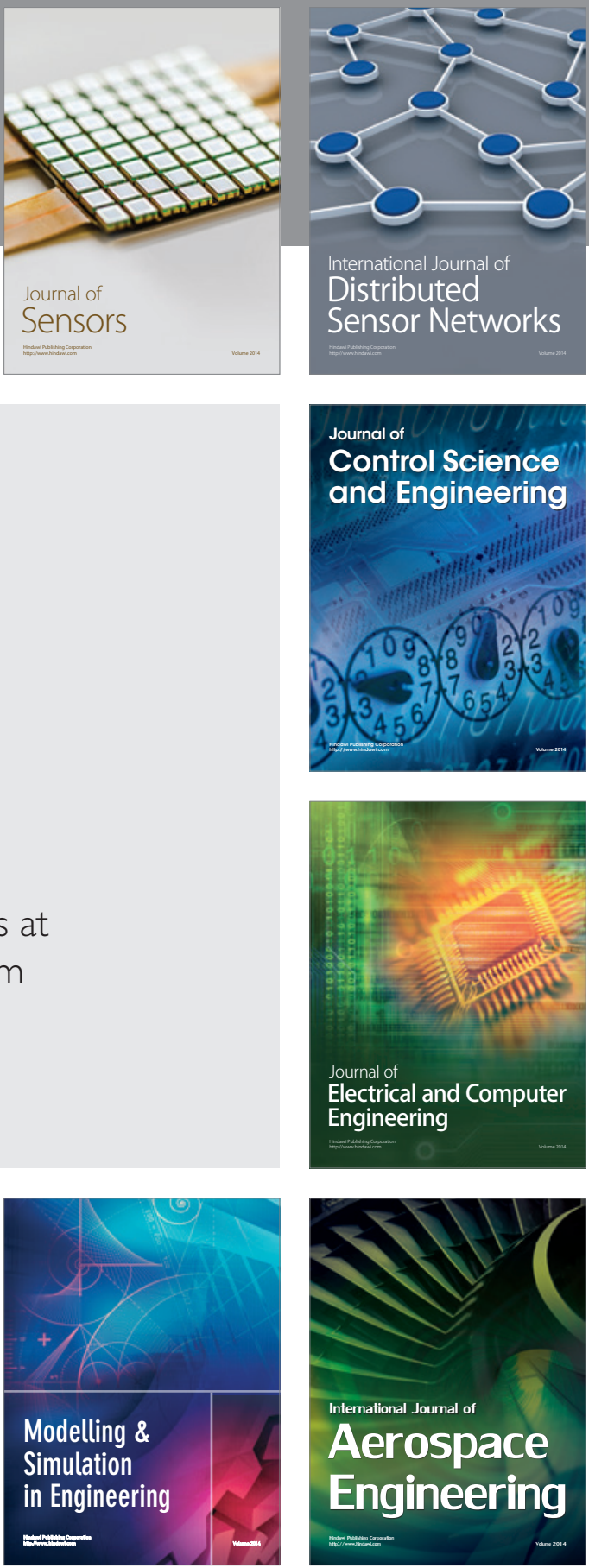

Journal of

Control Science

and Engineering
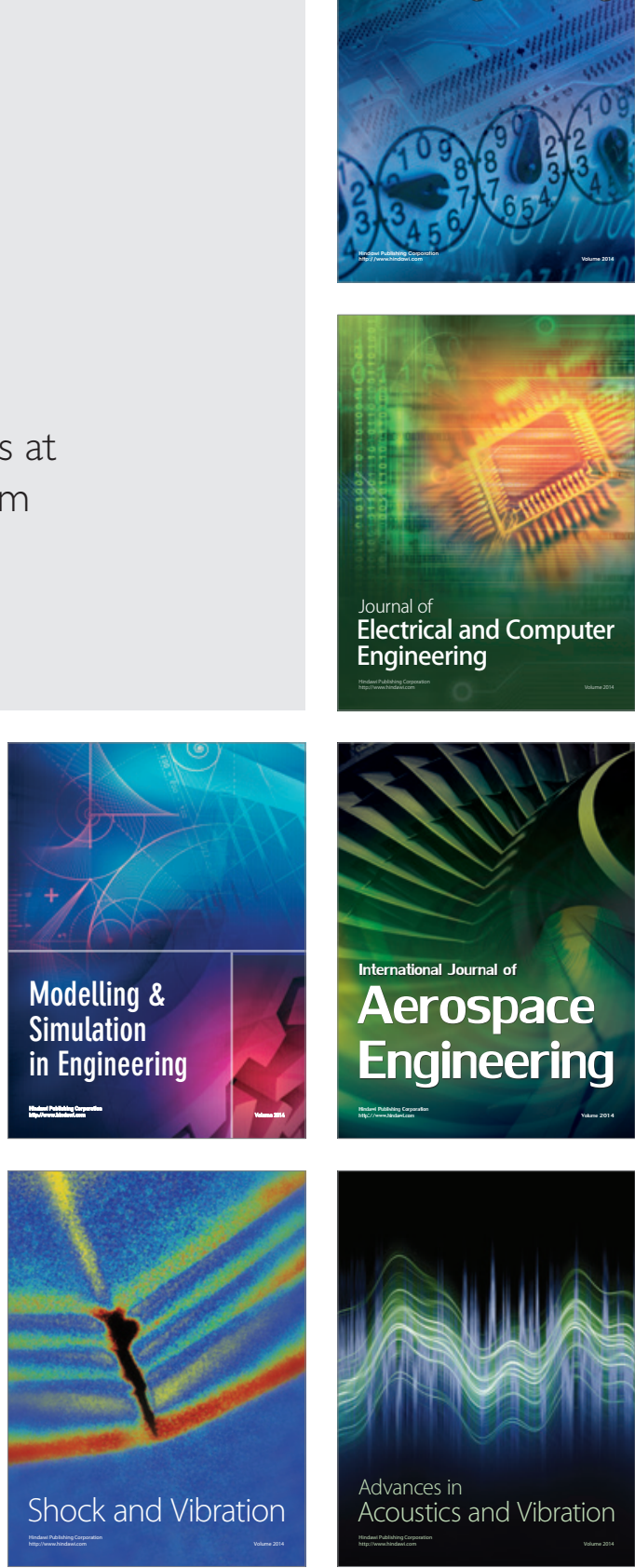